\title{
A study of nurses' job satisfaction: The relationship to professional commitment and friendship networks
}

\author{
Li-Se Yang ${ }^{1}$, Hsieh-Hua Yang ${ }^{2 *}$, Hsiu-Tzu Chen ${ }^{3}$, Mei-Fang Chang ${ }^{1}$, Yu-Fen Chiu ${ }^{1}$, \\ Ya-Wen $\mathrm{Chou}^{1}$, Yen-Chi Cheng ${ }^{1}$ \\ ${ }^{1}$ Department of Nursing, En Chu Kong Hospital, New Taipei City, Chinese Taipei; \\ ${ }^{2}$ Department of Health Care Administration, Oriental Institute of Technology, New Taipei City, Chinese Taipei; \\ ${ }^{*}$ Corresponding Author: yansnow@gmail.com \\ ${ }^{3}$ Nursing Home of Huaining Internal Medicine Clinic, Taoyuan, Chinese Taipei
}

Received 30 August 2012; revised 1 October 2012; accepted 14 October 2012

\begin{abstract}
We suggest that employees' job satisfaction has relationship to friendship network other than professional commitment, and argue that friendship network in the same ward and across wards will have different effects on employees' job satisfaction. A cross-sectional survey design utilizing questionnaires was selected to fulfill the research objectives. All of the 405 nurses in the En Chou Kong Hospital were surveyed. Three hundred and three nurses completed the questionnaire representing a response rate of $74.8 \%$. The instruments included friendship network nomination, professional commitment scale, and nurses' job satisfaction scale (NJSS). The regression model of job satisfaction was constructed, using friendship network variables in the ward and across wards and professional commitment as independent variables. $R$ square for each model is $0.22-0.36$ for the four dimensions of job satisfaction. Professional commitment is the robust predictor. The efficiency of friendship network in the ward is a good predictor, while it is negative related to satisfaction of work load. Further, the indegree in the ward is negative related to work load. Implication was discussed.
\end{abstract}

Keywords: Job Satisfaction; Professional Commitment; Friendship Network

\section{INTRODUCTION}

Employees who have friends at work are more likely to be engaged in their jobs. A review or research suggests that workplace friendship is positively related to employees' job satisfaction, performance, team cohesion, and organizational commitment; it is negatively associated with employees' turnover intentions and negative emotions [1-4]. Job satisfaction is perhaps the most widely studied work orientation over the last four decades of organizational research. It is obviously complex because of a multitude of variables associated with it [5]. A literature review [6-7] revealed that the absence of a robust causal model incorporating organizational, professional and personal variables is undermining the development of interventions to improve nurse retention. It is suggested that friendship at work may make up the puzzling absence.

In the review [6], organizational commitment, cohesion of the ward nursing team were identified as the strong predictors of job satisfaction, and professional commitment, communication with supervisor/peers were moderate correlated with job satisfaction. Since it had been proposed that professional commitment might escalate in importance as a compensation for the loss of organizational commitment [8]. It is argued that job satisfaction has relationship to professional commitment and friendship network.

Professional commitment is a person's involvement, pledge, promise or resolution towards his/her profession [8]. Fang's study of Singaporean nurses demonstrated that job satisfaction was significantly and positively related to professional commitment, the correlation parameter was 0.347 [9]. In another study [10], professional commitment is positively related to the job satisfaction of nurses, $r=0.386$. [11] tested that overall job attitude is fundamentally important for understanding work behavior. However, [12] discovered that professsional role conception and job satisfaction were strongly negatively related at the time of hire and posited that the newly graduated nurse, faced with discrepancies between her school-taught values and practices and the values and practices of her workplace, may develop alienation and job dissatisfaction. According to this finding, the tenure 
should be considered in predicting job satisfaction.

The cohesiveness of the ward nursing team was mentioned as a strong predictor of job satisfaction [6]. The basic element of cohesive team is friendship network. Literature documents that individuals will have benefits through their social networks. [13] found the issues in interpersonal relationships were frequently cited causes that made nurses consider leaving their jobs. [14] found social support might reduce personnel turnover in hospitals. Greater social support and pay can reduce turnover by their positive impact on job satisfaction [15]. In Taiwan, [16] showed that interpersonal relationship was the highest factor of job satisfaction. And, the research in a Norwegian population of nurses found that interaction, followed by pay and autonomy were the most important job factors [17]. In organizational settings, [18] convincingly argued, the social relations of the workplace may make a key contribution to employees' job satisfaction, productivity, and well-being. Friendship network can be used as a measurement of social relations, but not ever a direct measurement was applied to evaluate this variable.

Nurses bring to their job more than just the professional abilities they have accumulated through years of education and experience. They also bring the assets they can procure through their social network. The researchers identified two main approaches in which social networks can enhance individual and organizational performance. First, social networks can facilitate access to information, resources, and opportunities [19-24]. Second, networks can help actors to coordinate critical task interdependencies and to overcome the dilemmas of cooperation and collective action [25-29].

The traditional view of social capital stresses the positive effects of "network closure" in promoting a normative environment that facilitates trust and cooperation between actors [22,30]. Structural hole theory proposes an alternative view of the relationship between network structure and the benefits of social capital [23,24]. The structural hole theory argues that the benefits from social capital stem from the brokerage opportunities created by disperse ties $[23,24]$. Although structural hole theory is mainly concerned with the sources of competitive advantage, [24] also sees the autonomy of players as crucial asset to promote effective coordination in organizations.

Workplaces often have features that may facilitate friendship making. As nurses work in the ward nursing team, the workplace friendship in the working ward can help to facilitate coordination, cooperation, interdependencies and promote the job satisfaction. They can also meet others of other wards and make cross-ward friendships. Cross-ward friendships can provide extensive contact in multiple departments with access to information, resources, and opportunities. Obviously, there is difference between the friendship in working ward and across wards.

We test the hypotheses through a social network lens by examining friendship network of nurses in a hospital in Taiwan. The objectives of this research are illustrating the friendship network in the same ward and across wards, and constructing the model of job satisfaction.

\section{METHOD}

A cross-sectional survey design utilizing questionnaires was selected to fulfill the research objectives. All of the 405 nurses in the En Chou Kong Hospital were surveyed. Three hundred and three nurses completed the questionnaire representing a response rate of $74.8 \%$. The instruments included social network nomination, professional commitment scale, and nurses' job satisfaction scale (NJSS).

Social network nomination was applied to derive the participants' friendship networks. The participants were asked to nominate up to 18 persons either in the same ward or across wards separately.

Professional commitment scale is a 6-point Likert type scale $(1=$ strongly disagree, $6=$ strongly agree) with 3 items. These 3 items are "Being a professional nurse is great helpful to my self-image", "I am proud of being a professional nurse", and "I am enthusiastic about nursing care". The Cronbach's alpha was 0.83 .

The NJSS was adopted from [31]. It was applied to measure job satisfaction in 4 domains of job environment, human relationship, feedback, and benefit and promotion. The questions were scored on a 6-point Likert scale ranging from 1 point (very dissatisfied) to 6 points (very satisfied). The measurement has strong internal consistency with all multiple-item constructs achieving Cronbach's alpha ranged between 0.89 and 0.98 , exceeding the 0.7 threshold commonly suggested for exploratory research [32]. The construct validity is shown as Table $\mathbf{1}$.

Prior to data collection, approval to conduct the study was obtained from the Medical Center and the participants signed an agreement.

Excel was applied to data coding and processing. UCINET 6 for window [33] was used to calculate the social network variables. The nomination number is defined as outdegree and the number of nominated as indegree. Efficiency is effective size divided by observed size [23]. The equations is shown as below. The Statistical Package for the Social Sciences (SPSS) software was used to describe the data and construct the regression model.

$$
\text { Effective size }=\sum_{j}\left[1-\sum_{q} p_{i q} m_{j q}\right], q \neq i, j
$$


Table 1. Convergent/discriminant validity of NJSS.

\begin{tabular}{|c|c|c|c|c|}
\hline Construct \& item & Factor 1 & Factor 2 & Factor 3 & Factor 4 \\
\hline \multicolumn{5}{|l|}{ Benefit and promotion } \\
\hline The promotion system & 0.86 & & & \\
\hline The equity of the pursing personal development & 0.83 & & & \\
\hline The pursing personal development & 0.82 & & & \\
\hline The equity of the promotion system & 0.81 & & & \\
\hline The welfare system & 0.68 & & & \\
\hline The on-the-job training meets my needs & 0.60 & & & \\
\hline \multicolumn{5}{|l|}{ Human relationship } \\
\hline The working climate & & 0.78 & & \\
\hline Getting along with my direct manager & & 0.74 & & \\
\hline The group cooperation & & 0.69 & & \\
\hline The work devotion of my colleagues & & 0.67 & & \\
\hline Cooperation with other units & & 0.65 & & \\
\hline The support from head nurse & & 0.64 & & \\
\hline The affirmation of nursing role from other health professionals' viewpoint & & 0.46 & & \\
\hline \multicolumn{5}{|l|}{ Work load } \\
\hline The over-time condition of my work & & & 0.86 & \\
\hline My working loading & & & 0.73 & \\
\hline The arrangement of work rotation & & & 0.63 & \\
\hline \multicolumn{5}{|l|}{ Job environment } \\
\hline The supply condition & & & & 0.88 \\
\hline The renovation of instrument & & & & 0.83 \\
\hline The environment security & & & & 0.64 \\
\hline Eigenvalue & 4.52 & 3.82 & 2.32 & 2.17 \\
\hline$\%$ of variance & 23.81 & 20.08 & 12.19 & 11.44 \\
\hline Cumulative $\%$ of variance & 23.81 & 43.89 & 56.08 & 67.52 \\
\hline
\end{tabular}

Efficiency $=$ effective size/observed size

\section{RESULT}

The participants came from 17 wards in a hospital. As Table 2, there are 301 females and 2 males. Since the percentage of males is 0.7 , the gender difference is not included in regression model. Over half of the participants are graduated from college, one third of them are from university, and the others are from high schools. The mean tenure in present ward is 4.26 years, and the longest tenure is 14 years. The mean score of professional commitment is 12.56 .

Three social network variables, outdegree, indegree, and efficiency, were calculated. Outdegree is the nomination number for each participant. Indegree is the number nominated by others for each participant. Efficiency represents the effective size divided by observed size. In the same ward, the mean scores of outdegree, indegree, and efficiency are $3.80,3.80$, and 0.65 . Across different wards, the mean scores of outdegree, indegree, and efficiency are $0.93,0.93$, and 0.56 . And the mean scores of job satisfaction for all dimensions were moderate.

The regression model of job satisfaction was constructed, using friendship network variables in the ward and across wards and professional commitment as independent variables with tenure and education as control 
Table 2. Description of participants.

\begin{tabular}{|c|c|c|}
\hline Variables & $\mathrm{N}$ & $\%$ \\
\hline \multicolumn{3}{|l|}{ Gender } \\
\hline Male & 2 & 0.7 \\
\hline Female & 301 & 99.3 \\
\hline \multicolumn{3}{|l|}{ Education } \\
\hline High school & 26 & 8.6 \\
\hline College & 163 & 53.8 \\
\hline \multirow[t]{2}{*}{ University } & 114 & 37.6 \\
\hline & Mean & SD \\
\hline Tenure $(0-14)$ & 4.26 & 3.96 \\
\hline Professional commitment (6 - 18) & 12.56 & 1.97 \\
\hline \multicolumn{3}{|l|}{ Friendship network in the ward } \\
\hline Outdegree $(0-17)$ & 3.80 & 3.60 \\
\hline Indegree $(0-11)$ & 3.80 & 2.52 \\
\hline Efficiency $(0-1.00)$ & 0.65 & 0.22 \\
\hline \multicolumn{3}{|l|}{ Friendship network across wards } \\
\hline Outdegree $(0-12)$ & 0.93 & 1.87 \\
\hline Indegree $(0-9)$ & 0.93 & 1.38 \\
\hline Efficiency $(0-1.00)$ & 0.56 & 0.48 \\
\hline \multicolumn{3}{|l|}{ Job satisfaction } \\
\hline Job environment ( 3 - 18) & 12.47 & 1.87 \\
\hline Human relationship (7 - 42) & 29.52 & 3.84 \\
\hline Benefit \& promotion (6 - 36) & 24.93 & 3.47 \\
\hline Work load (3 - 18) & 12.15 & 1.69 \\
\hline
\end{tabular}

variables. As Table 3, the results showed that $\mathrm{R}$ square for each model is $0.22-0.36$. For the four dimensions of job satisfaction, professional commitment is the robust predictor. The efficiency of friendship network in the ward is a good predictor for all the four dimensions, while it is negative related to work load. Further, the indegree in the ward is negative related to work load. For friendship network across wards, outdegree is a good predictor for job environment, and benefit \& promotion, and indegree is positive related to work load.

\section{DISCUSSION}

In this article the friendship networks in the working ward and across wards were examined. The results have several implications for the current debate on the relationship between social networks and social capital. And it would be acknowledged some limitations that recom- mend caution at the time of extracting conclusions, and suggest the importance of future research on the topic.

\subsection{Theoretical Implications}

Our research raises several theoretical and practical issues for the analysis of how friendship networks can enhance the nurses' job satisfaction. By analyzing the theoretical underpinnings of the network closure and structural hole theories of social capital, it is partially relieved for which the tension between two alternative views of the relationship between social structures and benefits purportedly created by those structures. The current debate suggests that networks rich in structural holes may provide the information necessary to find about new opportunities, but they may hinder the emergence and the enforcement of the norms that can secure cooperative behavior. Network closure is thus viewed as essential to obtain the support and the cooperation necessary to take advantage of the opportunities accessible to individuals through their ties. Yet, our results suggest that social context should be considered in interpreting this debate.

In the working ward, efficiency is positively related to job satisfaction in three dimensions, benefit \& promotion, human relationship, job environment. The nurse who has higher efficiency demonstrates her friendship network is rich in structural hoes and may take the advantage of the opportunities to obtain support to get her job done. And her job satisfaction will be promoted. This result supports the structural hole theory. Indegree refers to the number of other nurses to which a given nurse is directly connected. The higher indegree represents the nominated person has more friends in the working ward. Seers [34] defined team-member exchange as the relationship quality between an individual and her team members. The empirical evidence demonstrates that individuals who experience high-quality team-member exchange relationships are more likely to contribute by assisting one another and to share information, ideas, and feedback within work teams $[34,35]$. In a working ward, the nurse who has good relationship quality with others takes more time and energy to accomplish these contributions, and it will increase work load and reduce job satisfaction. This result indicates that network closure has negative effect on satisfaction of work load.

Across wards friendship has different feature. Efficiency across wards is not important any more. Outdegree across wards is helpful for job environment and benefit \& promotion, and indegree is helpful for work load. The results indicated that closer friendship across department can provide opportunities for accessing information of benefit \& promotion. Thus, the satisfaction will be increased. The friendship across wards extend 
Table 3. Regression model of job satisfaction.

\begin{tabular}{|c|c|c|c|c|}
\hline Variables & $\begin{array}{c}\text { Benefit \& promotion } \\
\text { B (s.e.) }\end{array}$ & $\begin{array}{l}\text { Human relationship } \\
\text { B (s.e.) }\end{array}$ & $\begin{array}{l}\text { Work load } \\
\text { B (s.e.) }\end{array}$ & $\begin{array}{c}\text { Job environment } \\
\text { B (s.e.) }\end{array}$ \\
\hline Constant & $13.21(1.24)$ & $15.81(1.33)$ & $7.92(0.63)$ & $7.98(0.71)$ \\
\hline Tenure & $-0.07(0.05)$ & $-0.04(0.05)$ & $0.02(0.02)$ & $-0.05(0.03)$ \\
\hline \multicolumn{5}{|l|}{ Education } \\
\hline Highschool/university & $0.94(0.68)$ & $1.28(0.73)$ & $-1.22(0.34)^{* * *}$ & $1.00(0.39)^{*}$ \\
\hline College/university & $0.19(0.36)$ & $-0.20(0.39)$ & $-0.25(0.18)$ & $-0.04(0.21)$ \\
\hline Professional commitment & $0.82(0.09)^{* * *}$ & $0.97(0.10)^{* * *}$ & $0.38(0.05)^{* * *}$ & $0.30(0.05)^{* * *}$ \\
\hline \multicolumn{5}{|c|}{ Friendship network in the ward } \\
\hline Outdegree & $-0.01(0.05)$ & $-0.03(0.06)$ & $0.03(0.03)$ & $-0.01(0.03)$ \\
\hline Indegree & $0.05(0.07)$ & $0.01(0.08)$ & $-0.08(0.04)^{*}$ & $0.01(0.04)$ \\
\hline Efficiency & $1.92(0.79)^{*}$ & $2.71(0.84)^{* *}$ & $-0.88(0.40)^{*}$ & $1.34(0.45)^{* *}$ \\
\hline \multicolumn{5}{|c|}{ Friendship network across wards } \\
\hline Outdegree & $0.24(0.11)^{*}$ & $0.21(0.12)$ & $-0.02(0.05)$ & $0.18(0.06)^{* *}$ \\
\hline Indegree & $0.20(0.16)$ & $0.23(0.17)$ & $0.20(0.08)^{*}$ & $-0.08(0.09)$ \\
\hline Efficiency & $-0.18(0.43)$ & $-0.54(0.46)$ & $0.29(0.22)$ & $-0.18(0.25)$ \\
\hline $\mathrm{R}$ & 0.56 & 0.60 & 0.52 & 0.46 \\
\hline R square & 0.31 & 0.36 & 0.27 & 0.22 \\
\hline
\end{tabular}

one's social networks and increase the opportunities to compare with other wards colleague. The social comparison theory [36] posited that there is a drive within individuals to look to outside images in order to evaluate their own opinions and ability. The nurses learn about their own attitudes by comparing themselves with other nurses across wards. Since the nurses work in the same hospital, they have reasonable similar job environment. The similarity will promote the satisfaction about job environment.

\subsection{Managerial Implications}

In this study, the friendship networks in the ward and across wards are different in structure. The outdegree in the same ward is higher than across wards. Apparently, the nurses have more friends in the working ward then out of the working ward. And the item "work load" was negatively correlated with indegree in the ward and positively correlated with indegree across ward. Obviously, the work burden came from the same ward but not from the other ward. The friendship network in a ward should be considered in the arrangement of working shift.

Professional commitment is a robust predictor of job satisfaction. The importance of employees' commitment has been widely advocated [37-40]. Commitment may provide an important source of occupational meaning. Professional commitment had an incremental effect on a professional's intention to leave the organization in one study [39]. Enhancing professional commitment in nursing has the potential to produce benefits for both the individual and their organization $[41,42]$. Further, the professional commitment is shaped during the socialization process. The development of a profession involves more than developing a distinct body of knowledge. It involves the realization that professionals are part of a moral community with social links not only to their clients and colleagues in the profession but also to other groups. The legitimacy of nursing's professional contribution must be acknowledged by other groups, including physicians and administrators or managers of health care facilities.

During the socialization process professional commitment is shaped and is encountered by individuals through professional experiences. It may be viewed as an exchange process or relationship between the individual and others in his or her professional and personal environments and with society as a whole. The hospital may create an opportunity for nurses to have the socialization processes that offer direct learning through didactic teaching and indirect learning through example and sustained involvement with others in the professional subsystem. Furthermore, similarity breeds connection [43]. 
The participants connect with their friends of the same value across divisions. And the attitude, belief, and value similarity lead to attraction and interaction [44]. The opportunity for interaction with the friends in ward and across wards would reinforce the professional commitment.

\subsection{Limitations and Future Research}

Although this study expands our knowledge of friendship network related to job satisfaction among nurses, it has limitations. First, as the data reported in this paper was obtained from all the nurses working in a single district hospital, it is rather difficult to make generalizations. The result might have differed if the population came from different hospital. Further, the task was relatively heterogeneous across these 17 departments. It is suggested that further research is needed to differentiate the effect of divisions.

The findings remind us the friendship may have negative effect. [45] indicated that the entrepreneurs did benefit from the support and resources provided by their cohesive networks, but the obligations that resulted from those benefits, and the entrepreneurs' difficulties to extricate themselves from those obligations, curtailed their subsequent ability to pursue new opportunities. The social capital embodies in their cohesive networks then became a liability that hindered, rather than helped, their subsequent performance. The research of the "dark side" of friendship network is needed.

\section{CONCLUSIONS}

Nursing is a healthcare profession. They work in a large variety of specialties and as part of a team. The interaction with team member is needed at their work. Interpersonal relationships play a pivotal role in effective team functioning because they facilitate behaviors that maximize the individual potential for team efficiency and effectiveness [46]. The friendship network of nurse is a key factor of job satisfaction.

However, the role of friendship network play different roles in working ward and across wards. In working ward, network efficiency is helpful for job satisfaction. And network closure across wards is helpful for job satisfaction. The findings of this study provide evidence for the importance of considering context when examining the debate between network closure and structural hole.

Social networks research focuses on patterns of social relations among a set of actors to explain social phenomena [47]. The utilization of social networks can explain how the interaction of an individual within broader social network of actors affects how perceptions of exchange relationships develop. We apply this logic and tested that social network will affect employees' perceptions of job satisfaction.

\section{REFERENCES}

[1] Berman, E.M., West, J.P. and Richter, M.N. (2002) Workplace relations: Friendship patterns and conesquences (according to managers). Public Administration Reviews, 62, 217-230. doi:10.1111/0033-3352.00172

[2] Morrison, R. (2004) Information relationships in the workplace: Association with job satisfaction, organizational commitment and turnover intentions. New Zealand Journal of Psychology, 33, 114-128.

[3] Riordan, C.M. and Griffeth, R.W. (1995) The opportunity for friendship in the workplace: An underexplored construct. Journal of Business and Psychology, 10, 141-154. doi:10.1007/BF02249575

[4] Winstead, B.A., Derlega, V.J., Montgomery, M.J. and Pilkington, C. (1995) The quality of friendships at work and job satisfaction. Journal of Social and Personal Relationships, 12, 199-215. doi:10.1177/0265407595122003

[5] Johnston, C.L. (1997) Changing care patterns and registered nurse job satisfaction. Holistic Nursing Practice, 11, 69-77.

[6] Lu, H., While, A.E. and Barriball, K.L. (2005) Job satisfaction among nurses: A literature review. International Journal of Nursing Studies, 42, 211-227. doi:10.1016/j.ijnurstu.2004.09.003

[7] Lu, H., Barriball, K.L., Zhang, X. and While, A.E. (2011) Job satisfaction among hospital nurses revisited: A systematic review. International Journal of Nursing Studies, 49, 1017-1038. doi:10.1016/j.ijnurstu.2011.11.009

[8] Irving, G.P., Coleman, D.F. and Cooper, C.L. (1997) Further assessments of a three-component model of organizational commitment: Generalizability and differences across occupations. Journal of Applied Psychology, 82 444-452. doi:10.1037/0021-9010.82.3.444

[9] Fang, Y. (2001) Turnover propensity and its causes among Singapore nurses: An empirical study. International Journal of Human Resource Management, 12, 859871. doi:10.1080/09585190110047875

[10] Lu, K.-Y., Lin, P.-L. Wu, C.-M., Hsieh, Y.-L. and Chang, Y.-Y. (2002) The relationship among turnover intentions, professional commitment, and job satisfaction of hospital nurses. Journal of Professional Nursing, 18, 214-219. doi:10.1053/jpnu.2002.127573

[11] Harrison, D.A., Newman, D.A. and Roth, P.L. (2006). How important are job attitudes? Meta-analytic comparesons of integrative behavioral outcomes and time sequences. Academy of Management Journal, 49, 305-325. doi:10.5465/AMJ.2006.20786077

[12] Ahmadi, K.S., Speedling, E.J. and Kuhn-Weissman, G. (1987) The newly hired hospital staff nurse's professionalism, satisfaction and alienation. Internal Journal of Nursing Studies, 24, 107-121. doi:10.1016/0020-7489(87)90053-8

[13] Takase, M., Oba, K. and Yamashita, N. (2009) Generational differences in factors influencing job turnover 
among Japanese nurses: An exploratory comparative design. International Journal of Nursing Studies, 46, 957967. doi:10.1016/j.ijnurstu.2007.10.013

[14] Bjorvell, H. and Brodin, B. (1992) Hospital staff members are satisfied with their jobs. Scandinavia Journal of Caring Sciences, 6, 9-16.

[15] Price, J.L. (2001) Reflections on the determinants of voluntary turnover. International Journal of Manpower, 22, 600-624. doi:10.1108/EUM0000000006233

[16] Chang, F.M., Lin, C.J., Kuo, H.W., Teng, Y.K. and Lee, J.N. (1995) Appraisal and satisfaction among staff nurses in the health stations of Taiwan province. China Journal of Public Health, 14, 78-87.

[17] Bjork, I.T., Samdal, G.B. Hansen, B.S., Torstad, S. and Hamilton, G.A. (2007) Job satisfaction in a Norwegian population of nurses: A questionnaire survey. International Journal of Nursing Studies, 44, 747-757. doi:10.1016/j.ijnurstu.2006.01.002

[18] Hodson, R. (1997) Group relations at work: Solidarity, conflict and relations with management. Work and Occupations, 24, 426-452. doi:10.1177/0730888497024004003

[19] Granovetter, M. (1974) Getting a job: A study of contacts and careers. University of Chicago Press, Chicago.

[20] Lin, N., Ensel, W. and Vaughn, J. (1981) Social resources and strength of ties: Structural factors in occupational status attainment. American Sociological Review, 46, 393405. doi: $10.2307 / 2095260$

[21] Flap, H.D. and de Graaf, N.D. (1986) Social capital and attained occupational status. Netherlands Journal of Sociology, 22, 145-161.

[22] Coleman, J.S. (1990) Foundations of social theory. Harvard University Press, Cambridge.

[23] Burt, R.S. (1992) Structural holes: The structure of competition. Harvard University Press, Cambridge.

[24] Burt, R.S. (1997) The contingent value of social capital. Administrative Science Quarterly, 42, 339-364. doi: $10.2307 / 2393923$

[25] Pfeffer, J. and Salancik, G.R. (1978) The external control of organizations: A resource dependence perspective. Harper \& Row, New York.

[26] Kotter, J.P. (1982) What effective general managers really do. Harvard Business Review, 60, 156-167.

[27] Gulati, R. (1995) Social structure and alliance formation patterns: A longitudinal analysis. Administrative Science Quarterly, 40, 619-652. doi:10.2307/2393756

[28] Walker, G., Kogut, B. and Shan, W.J. (1997) Social capital, structural holes and the formation of an industry network. Organization Science, 8, 109. doi:10.1287/orsc.8.2.109

[29] Gulati, R. and Gargiulo, M. (1999) Where do interiorganizational networks come from? American Journal of Sociology, 104, 1439-1493. doi:10.1086/210179

[30] Coleman, J.S. (1988) Social capital in the creation of human capital. American Journal of Sociology, 94, S95S120. doi: $10.1086 / 228943$

[31] Lin, C.J., Wang, H.C., Li, T.C. and Huang, L.C. (2007)
Reliability and validity of nurses' job satisfaction scale and nurses' professional commitment. Mid-Taiwan Journal of Medicine, 12, 65-75.

[32] Nunnally, J.C. (1978) Psychometric Theory. McGrawHill, New York.

[33] Borgatti, S.P., Everett, M.G. and Freeman, L.C. (2002) UCINET 6 for Windows: Software for social network analysis. Analytic Technologies, Harvard.

[34] Seers, A. (1989) Team-member exchange quality: A new construct for role-making research. Organizational Behavior and Human Decision Processes, 43, 118-135. doi:10.1016/0749-5978(89)90060-5

[35] Seers, A., Petty, M.M. and Cashman, J.F. (1995) Teammember exchange under team and traditional management. Group and Organization Management, 20, 18-38. doi: $10.1177 / 1059601195201003$

[36] Festinger, L. (1954) A theory of social comparison processes. Human Relations, 7, 117-140. doi: $10.1177 / 001872675400700202$

[37] Aryee, S. and Tan, K. (1992) Antecedents and outcomes of career commitment. Journal of Vocational Behavior, 40, 288-305. doi:10.1016/0001-8791(92)90052-2

[38] Bedeian, A.G. and Kemery, E.R. (1991) Career commitment and expected utility of present job as predictors of turnover intention and turnover behavior. Journal of Vocational Behavior, 39, 331-343. doi:10.1016/0001-8791(91)90042-K

[39] Blau, G. and Lunz, M. (1998) Testing the incremental effect of professional commitment on intent to leave one's profession beyond the effects of external, personal, and work-related variables. Journal of Vocational Behavior, 52, 260-269. doi:10.1006/jvbe.1997.1601

[40] Chang, E. (1999) Career commitment as a complex moderator of organizational commitment and turnover intention. Human Relations, 52, 1257-1278. doi:10.1023/A:1016908430206

[41] Cohen, A. (1998) An examination of the relationship between work commitment and work outcomes among hospital nurses. Scandinavia Journal of Management, 14, 1-17. doi:10.1016/S0956-5221(97)00033-X

[42] Cohen, A. (1999) Relationships among five forms commitment: An empirical assessment. Journal of Organizational Behavior, 20, 285-308.

doi:10.1002/(SICI)1099-1379(199905)20:3<285::AID-JO B887>3.0.CO;2-R

[43] McPherson, M., Smith-Lovin, L. and Cook, J.M. (2001) Birds of a feather: Homophily in social networks. Annual Review of Sociology, 27, 415-444. doi:10.1146/annurev.soc.27.1.415

[44] Huston, T.L. and Levinger, G. (1978) Interpersonal attraction and relationships. Annual Review of Psychology, 29, 115-156. doi:10.1146/annurev.ps.29.020178.000555

[45] Portes, A. and Sensenbrenner, J. (1993) Embeddedness and immigration: Notes on the social determinants of economic action. American Journal of Sociology, 98, 1320-1350. doi:10.1086/230191

[46] Kostova, T. and Roth, K. (2003) Social capital in multinational corporations and a micro-macro model of its 
formation. Academy of Management Review, 29, 297-317. doi:10.5465/AMR.2003.9416356

[47] Wasserman, S. and Faust, K. (1994) Social network analysis: Methods and applications. Cambridge University Press, Cambridge. doi:10.1017/CBO9780511815478 